\title{
Solar disinfection (SODIS) and subsequent dark storage of Salmonella typhimurium and Shigella flexneri monitored by flow cytometry

\author{
Correspondence \\ Thomas Egli \\ egli@eawag.ch
} \\ Received 1 October 2008 \\ Revised 17 December 2008 \\ Accepted 18 December 2008

\author{
Franziska Bosshard, ${ }^{1,2}$ Michael Berney, ${ }^{1} \dagger$ Michael Scheifele, ${ }^{1}$ \\ Hans-Ulrich Weilenmann ${ }^{1}$ and Thomas Egli ${ }^{1,2}$ \\ ${ }^{2}$ Institute of Biogeochemistry and Pollutant Dynamics, ETH Zürich, 8092 Zürich, Switzerland
}
${ }^{1}$ Eawag, Swiss Federal Institute of Aquatic Science and Technology, PO Box 611, CH-8600 Dübendorf, Switzerland

\begin{abstract}
Pathogenic enteric bacteria are a major cause of drinking water related morbidity and mortality in developing countries. Solar disinfection (SODIS) is an effective means to fight this problem. In the present study, SODIS of two important enteric pathogens, Shigella flexneri and Salmonella typhimurium, was investigated with a variety of viability indicators including cellular ATP levels, efflux pump activity, glucose uptake ability, and polarization and integrity of the cytoplasmic membrane. The respiratory chain of enteric bacteria was identified to be a likely target of sunlight and UVA irradiation. Furthermore, during dark storage after irradiation, the physiological state of the bacterial cells continued to deteriorate even in the absence of irradiation: apparently the cells were unable to repair damage. This strongly suggests that for S. typhimurium and Sh. flexneri, a relatively small light dose is enough to irreversibly damage the cells and that storage of bottles after irradiation does not allow regrowth of inactivated bacterial cells. In addition, we show that light dose reciprocity is an important issue when using simulated sunlight. At high irradiation intensities $\left(>700 \mathrm{~W} \mathrm{~m}^{-2}\right.$ ) light dose reciprocity failed and resulted in an overestimation of the effect, whereas reciprocity applied well around natural sunlight intensity $\left(<400 \mathrm{~W} \mathrm{~m}^{-2}\right)$.
\end{abstract}

\section{INTRODUCTION}

The availability of safe drinking water is a key health issue in developing countries. The United Nations have declared it a millennium development goal to reduce the number of people without sustainable access to safe drinking water by half by 2015. Solar disinfection (SODIS) is one of the means to reach this goal. Its success is based on easily available and low-cost tools: one day of exposure to the sun of hygienically unsafe drinking water in PET bottles leads to a significant increase in microbiological water quality. A positive impact on health has been documented in several epidemiological field studies, e.g. in India, where a total of $40 \%$ of diarrhoeal diseases and $50 \%$ of severe diarrhoea episodes were prevented by the use of SODIS (Rose et al., 2006). SODIS water treatment is already used by 2 million people and the number is increasing. But despite the fact that the method works, the exact mechanism of inactivation of microbial pathogens is not yet known. Therefore, it

tPresent address: Department of Microbiology and Immunology, University of Otago, PO Box 56, Dunedin 9016, New Zealand.

Abbreviations: $\mathrm{DiBAC}_{4}(3)$, bis-(1,3-dibutylbarbituricacid)trimethine oxonol; EB, ethidium bromide; 2-NBDG, 2-[N-(7-nitrobenz-2-oxa-1,3-diazol4-yl)amino]-2-deoxy-D-glucose; PET, poly(ethylene terephthalate); PI, propidium iodide. is crucial to understand the way in which SODIS damages bacteria - and whether repair can occur.

The effectiveness of SODIS has been proven by cultivationbased techniques with Escherichia coli and some pathogenic organisms (Acra et al., 1980; Berney et al., 2006b; McGuigan et al., 1998; Wegelin et al., 1994), and recently we have applied cultivation-independent methods to characterize the inactivation of $E$. coli by sunlight (Berney et al., 2006a). In that study we used flow cytometry combined with viability staining to characterize the loss of essential cellular functions in irradiated bacterial cells. The recorded cellular functions include membrane integrity, membrane potential, efflux pump activity and glucose uptake activity. We showed that a reproducible sequence of membrane-function breakdown takes place when E. coli is irradiated with sunlight or UVA light (Berney et al., 2006a). However, it is important to know whether these results translate to enteric pathogens like Salmonella or Shigella, the inactivation of which is the primary goal of SODIS. So far this has not been investigated.

Reliability of the SODIS method depends not only on the light dose leading to damage in target cells, but also on possible recovery processes in injured cells after irradiation. So far, no regrowth or recovery of membrane functions in 
injured E. coli cells has been found (Berney et al., 2006a; Joyce et al., 1996; Oates et al., 2003; Reed, 1997; Wegelin et al., 1994).

The present work extends our knowledge about the inactivation mechanism of solar light from the indicator bacterium E. coli to two important enteric pathogens, Salmonella typhimurium and Shigella flexneri. In addition, we have investigated the ability of these enteric pathogens to survive and repair damage after solar irradiation.

\section{METHODS}

Bacterial strains. Salmonella enterica serovar Typhimurium ATCC 14028 (referred to in this paper as Salmonella typhimurium) and Shigella flexneri ATCC 12022 were used in this study.

Growth media and cultivation conditions. Cells were grown as described by Berney et al. (2006a) with modifications. In drinking water, cells grow very slowly or not at all; therefore, we used stationary-phase cells, which were shown to be more resistant to SODIS than cells in the exponential growth phase (Berney et al., 2006b; Reed, 1997). Luria-Bertani (LB) broth, which was filtersterilized with membrane filters $(0.22 \mu \mathrm{m}$, Millipore $)$ and diluted to $33 \%(\mathrm{v} / \mathrm{v})$ of its original strength with ultrapure water, was used for batch cultivation. Precultures were prepared for each individual batch experiment from the same cryo-vial, streaking the stock solution onto Hektoen agar plates (Oxoid) selective for Shigella and Salmonella species. After $15-18 \mathrm{~h}$ of incubation at $37^{\circ} \mathrm{C}$, one colony was picked, loop-inoculated into a $125 \mathrm{ml}$ Erlenmeyer flask containing $20 \mathrm{ml} \mathrm{LB}$ broth, and incubated at $37{ }^{\circ} \mathrm{C}$ on a rotary shaker at 200 r.p.m.. At an $\mathrm{OD}_{546}$ between 0.1 and 0.2 , an aliquot of the culture appropriate to obtain an initial $\mathrm{OD}_{546}$ of 0.002 was transferred into a $500 \mathrm{ml}$ Erlenmeyer flask containing $50 \mathrm{ml}$ prewarmed LB broth. With this procedure, no lag phase was observed. These flasks were then shaken at 200 r.p.m. on a rotary shaker at $37{ }^{\circ} \mathrm{C}$ for approximately $18 \mathrm{~h}$ until stationary phase was reached. Stationary phase was confirmed from five consecutive $\mathrm{OD}_{546}$ measurements within $1 \mathrm{~h}$.

Sample preparation and plating. Cells were harvested from batch culture by centrifugation $(16000 \mathrm{~g}$, 3min), washed three times with filter-sterilized commercially available bottled water (Evian) and diluted to an $\mathrm{OD}_{546}$ of approximately 0.01 (corresponding to $1-$ $5 \times 10^{7}$ cells $\mathrm{ml}^{-1}$ ). To allow the cells to adapt to the mineral water, light exposure of bacterial suspensions was not started until $1 \mathrm{~h}$ after dilution. During exposure, aliquots were withdrawn at different time points and diluted in decimal steps $\left(10^{-1}\right.$ to $\left.10^{-6}\right)$ with sterile-filtered bottled mineral water (Evian). Volumes of $1 \mathrm{ml}$ of appropriate dilutions were withdrawn and mixed with $7 \mathrm{ml}$ liquid tryptic soy agar (TSA) (Biolife) at $45{ }^{\circ} \mathrm{C}$ (pour-plate method). After $20 \mathrm{~min}$, the solidified agar was covered with another $4 \mathrm{ml}$ liquid TSA $\left(40{ }^{\circ} \mathrm{C}\right)$. Plates were incubated for $48 \mathrm{~h}$ at $37{ }^{\circ} \mathrm{C}$ until further analysis. The standard error of pour plating was always $<10 \%$.

Sunlight and UVA exposure. Samples of $10 \mathrm{ml}$ bacterial suspension (see above) were exposed to sunlight or UVA light as described earlier (Berney et al., 2006a, b, 2007).

Dark storage. Samples of $10 \mathrm{ml}$ bacterial suspension were exposed to UVA light (see above). Cellular damages were assessed immediately after irradiation and at different time points during dark storage, which was performed at $37{ }^{\circ} \mathrm{C}$ for $48 \mathrm{~h}$, holding the cells in the same medium (sterile-filtered bottled water) as during irradiation. To exclude the possibility of regrowth, nalidixic acid was included in all the samples at a concentration of $100 \mu \mathrm{g} \mathrm{ml}^{-1}$.
Staining procedures. Five fluorescent dyes were used alone or in different combinations: Syto 9 (Invitrogen Molecular Probes), propidium iodide (PI; Invitrogen), bis-(1,3-dibutylbarbituricacid)trimethine oxonol $\left(\mathrm{DiBAC}_{4}(3)\right.$; Invitrogen), ethidium bromide (EB; Fluka) and 2-[N-(7-nitrobenz-2-oxa-1,3-diazol-4-yl)amino]-2-deoxyD-glucose (2-NBDG; Invitrogen). Samples taken from irradiation experiments (sunlight and artificial UVA) were divided into five subsamples and immediately stained with two mixtures of fluorescent dyes (Syto 9/PI and Syto 9/EB) and three single fluorescent dyes [DiBAC $4(3)$, Syto 9 and 2-NBDG]. Samples were incubated in the dark at $37{ }^{\circ} \mathrm{C}$ for $5 \mathrm{~min}$ (2-NBDG) or at room temperature for $10 \mathrm{~min}\left[\mathrm{DiBAC}_{4}(3)\right], 15 \mathrm{~min}$ (Syto 9/EB), $20 \mathrm{~min}$ (Syto 9/PI) and $25 \mathrm{~min}$ (Syto 9), respectively, before analysis. Prior to flow-cytometric analysis, samples $\left(\sim 1-5 \times 10^{7}\right.$ cells $\left.\mathrm{ml}^{-1}\right)$ were diluted with sterilefiltered bottled water (Evian) to $1 \%(\mathrm{v} / \mathrm{v})$ of the initial cell concentration $\left(\sim 1-5 \times 10^{5}\right.$ cells $\mathrm{ml}^{-1}$ final concentration). Stock solutions of the dyes were prepared as follows: PI and Syto 9 were used from the LIVE/DEAD BacLight kit (Invitrogen), EB was prepared in distilled and filtered water at $25 \mathrm{mM}, \operatorname{DiBAC}_{4}(3)$ was prepared in DMSO at $10 \mathrm{mM}$, and 2-NBDG was dissolved in distilled and filtered water at $5 \mathrm{mM}$. All stock solutions were stored at $-20{ }^{\circ} \mathrm{C}$. The working concentrations of Syto 9, PI, EB, $\operatorname{DiBAC}_{4}(3)$ and 2NBDG were 5, 30, 30, 10 and $5 \mu \mathrm{M}$, respectively. 2-NBDG was added in combination with 2,4-dinitrophenol (final concentration $2 \mathrm{mM}$ ) (Natarajan \& Srienc, 2000). At the beginning of each experiment a sample was incubated at $90{ }^{\circ} \mathrm{C}$ for $3 \mathrm{~min}$ (in a $2 \mathrm{ml}$ Eppendorf tube) as a control measurement for inactive bacteria. By comparing the staining pattern of heat-inactivated with untreated samples, electronic gates were set to differentiate negatively and positively stained populations (Berney et al., 2008).

Flow-cytometric measurements. The methods used here have been described recently (Berney et al., 2006a, 2007). Flow-cytometric measurements were made using a Partec Cyflow space flow cytometer with $488 \mathrm{~nm}$ excitation from an argon ion laser running at $50 \mathrm{~mW}$ or (for the fluorescent glucose analogue 2-NBDG) $200 \mathrm{~mW}$. Green fluorescence was collected in the FL1 channel $(520 \pm 20 \mathrm{~nm})$, and red fluorescence in the FL3 channel $(>590 \mathrm{~nm})$; all data were processed with the Flowmax software (Partec), and electronic gating with the software was used to separate positive signals from noise. The specific instrumental gain settings for these measurements were as follows: $\mathrm{FL} 1=490$, FL3 $=600$, speed 3 (implying an event rate never exceeding 1000 events $\left.\mathrm{s}^{-1}\right)$. All samples were collected as logarithmic (3 decades) signals and were triggered on the green fluorescence channel (FL1). A routine check of the flow cytometer was performed every day for correct alignment with an FITC bead standard. This ensured accuracy in counting (volumetric counting device) and measured fluorescence intensities. Microscopic observation was performed on an Olympus BX50 microscope equipped with filters HQ-F41-007 for PI and EB and HQ-F41-001 for Syto 9, $\operatorname{DiBAC}_{4}(3)$ and 2-NBDG (all from AF Analysetechnik).

Total ATP. For the determination of total ATP, the BacTiter-Glo system (Promega) was used. The BacTiter-Glo buffer was mixed with the lyophilized BacTiter-Glo substrate and equilibrated at room temperature. The mixture was stored overnight at room temperature to ensure that all ATP was hydrolysed ('burned off') and the background signal had decreased. A cell suspension of $100 \mu \mathrm{l}$ was mixed in a $2 \mathrm{ml}$ Eppendorf tube with an equal volume of the previously prepared BacTiter-Glo reagent (stored on ice). The sample was then briefly mixed by once pipetting up and down and put into a water bath at $37{ }^{\circ} \mathrm{C}$ for $30 \mathrm{~s}$. The luminescence of the sample was measured in a luminometer (model TD-20/20; Turner BioSystems) immediately after incubation. A calibration curve with dilutions of pure rATP (Promega, P1132) was measured for each batch of BacTiter-Glo buffer. ATP concentration per cell was then calculated 
using this calibration curve and the total count measurements (Syto 9) from flow cytometry.

Reproducibility. All field experiments were conducted in three biological replicates on three different days. Irradiation intensity data were obtained from a weather station located $300 \mathrm{~m}$ from the exposure site (BAFU/NABEL, EMPA Dübendorf, Switzerland). Sunlight intensity varied with the weather conditions, so the light dose at the sampling points was never exactly the same. Therefore, we show representative results.

\section{RESULTS}

\section{Artificial UVA light exposure}

The susceptibility of different properties of S. typhimurium and Sh. flexneri to artificial UVA light is shown in Table 1. Both organisms were less susceptible to UVA light than the indicator bacterium E. coli (Berney et al., 2006a). For example, when assessed with PI staining, the light dose needed for membrane permeabilization of S. typhimurium was approximately three times, and for Sh. flexneri approximately two times, higher than for E. coli. However, for all three enteric bacteria, the same sequential inactivation pattern was observed with the measured viability indicators.

Because of this higher resistance, some of the laboratory experiments were conducted with much higher irradiation intensities than those normally achieved with natural sunlight. Typically, the maximum natural sunlight intensity at noon on mid-European longitude is about $130 \mathrm{~W}$ $\mathrm{m}^{-2}$ (integrated for the wavelength spectrum 350$450 \mathrm{~nm}$ ), whereas in this study, intensities between $163 \mathrm{~W} \mathrm{~m}^{-2}$ and $1315 \mathrm{~W} \mathrm{~m}^{-2}$ were used for artificial UVA exposure to achieve high enough fluences within a reasonable time period. We observed that, as soon as natural irradiation conditions were exceeded two- to threefold, the reciprocity law started to fail not only for the culturability of Sh. flexneri (Fig. 1) but also for all other measured viability indicators (data not shown). This clearly demonstrates that for these enteric pathogens high irradiation intensities in laboratory experiments result in an overestimation of the effect in comparison with the same light dose under natural sunlight conditions and that such data are hence of limited use. Therefore, the doses listed in Table 1 were obtained exclusively from experiments performed at light intensities that were in the range of natural conditions.

The difference in the fluence needed to achieve a three-log reduction when exposing the cells to different light intensities was a result of two effects. Firstly, the shape of the inactivation curve followed the 'log-linear with a shoulder' model for samples irradiated with natural sunlight or artificial UVA of a corresponding intensity. However, the shoulder disappeared when cells were irradiated with very high intensities (919 $\mathrm{W} \mathrm{m}^{-2}$ and $1315 \mathrm{~W} \mathrm{~m}^{-2}$ in Fig. 1). Secondly, the inactivation was three times faster with very high intensities as compared to natural conditions (slope of -0.0031 for intensities around $360 \mathrm{~W} \mathrm{~m}^{-2} \mathrm{vs}-0.0011$ with intensities around $1100 \mathrm{~W} \mathrm{~m}^{-2}$ ).

In general, the reciprocity law was valid for Sh. flexneri as long as intensities not exceeding $400 \mathrm{~W} \mathrm{~m}^{-2}$ were applied. Experiments conducted in this irradiation intensity range compared well with natural conditions. Reciprocity for $S$. typhimurium held over a much wider range (from 50 to $700 \mathrm{~W} \mathrm{~m} \mathrm{~m}^{-2}$ ). However, when very high irradiation intensities $\left(1000 \mathrm{~W} \mathrm{~m}^{-2}\right)$ were applied, the shoulder of the inactivation curve was shortened (data not shown).

\section{Sunlight exposure}

A decrease in culturability of more than $99 \%$ was observed (Figs 2a and 3a) for S. typhimurium and Sh. flexneri during

Table 1. Comparision of the susceptibility of S. typhimurium and Sh. flexneri to artificial UVA light and sunlight

Figures indicate the approximate light doses $( \pm 20 \%)$ in $\mathrm{kJ} \mathrm{m}^{-2}$ at which $>90 \%$ of the cells exhibited the properties indicated. Cells were exposed continuously to artificial UVA light with an intensity of $620 \mathrm{~W} \mathrm{~m}^{-2}$ for S. typhimurium and $360 \mathrm{~W} \mathrm{~m}^{-2}$ for Sh. flexneri. In the case of sunlight, cells were exposed during two consecutive days with a night break of approximately $12 \mathrm{~h}$. Sunlight exposure on the first day reached $2300 \mathrm{~kJ} \mathrm{~m}^{-2}$ for $S$. typhimurium and $2500 \mathrm{~kJ} \mathrm{~m}^{-2}$ for Sh. flexneri, respectively. An asterisk $\left(^{*}\right)$ indicates that this parameter changed during the night break. For comparison, corresponding data for E. coli are shown (Berney et al., 2006a).

\begin{tabular}{|c|c|c|c|c|c|c|}
\hline & \multicolumn{2}{|c|}{ S. typhimurium } & \multicolumn{2}{|c|}{ Sh. flexneri } & \multicolumn{2}{|l|}{ E. coli } \\
\hline & Artificial UVA & Sunlight & Artificial UVA & Sunlight & Artificial UVA & Sunlight \\
\hline $\begin{array}{l}\text { ATP level decreased to }<10 \% \text { compared to } \\
\text { control at }\end{array}$ & 2000 & 1500 & 1000 & 1000 & 300 & 700 \\
\hline Loss of culturability ( $0.1 \%$ survival) at & 3000 & $2300^{*}$ & 1800 & 1800 & 1700 & 1700 \\
\hline$>90 \%$ of cells with inactivated efflux pumps at & 3000 & $2300^{*}$ & 2000 & 2000 & 1000 & 1700 \\
\hline$>90 \%$ of cells unable to take up glucose at & 3500 & $2300^{*}$ & 3000 & 3000 & 2000 & 2000 \\
\hline$>90 \%$ of cells with depolarized membranes at & 6000 & $2300^{*}$ & 4500 & $2500^{*}$ & 1900 & 1700 \\
\hline$>90 \%$ of cells with permeabilized membranes at & 8000 & 4500 & 6000 & 4500 & 2400 & $-\dagger$ \\
\hline
\end{tabular}

$\dagger$ Not achieved. 


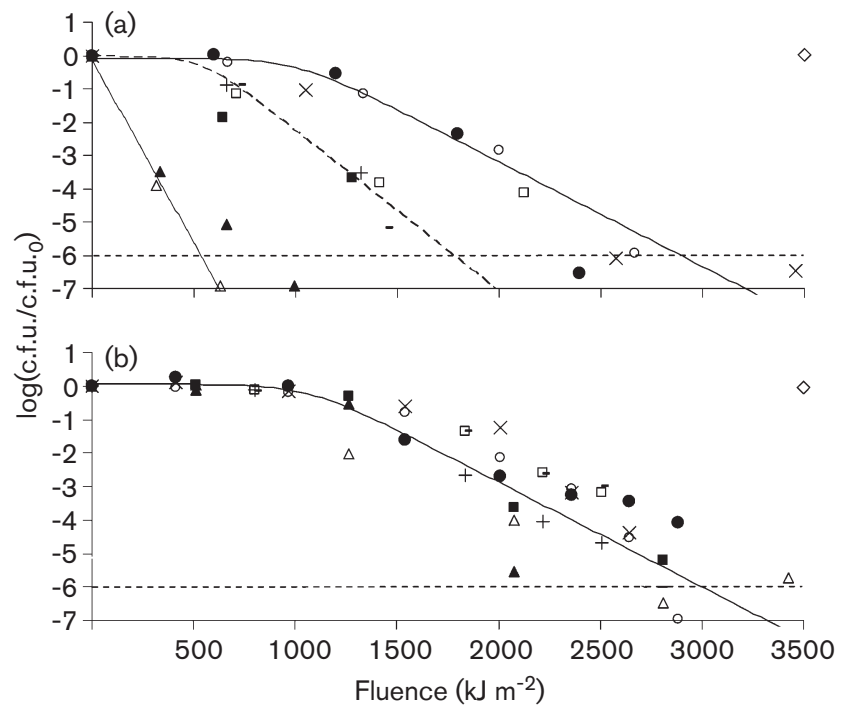

Fig. 1. Deviations from light dose reciprocity appearing with different intensities of artificial UVA light irradiation in comparison to long, low-intensity irradiation with sunlight, shown for the culturablity of Sh. flexneri. Bacterial cells were harvested from the stationary phase of an LB batch culture, washed three times and diluted in bottled mineral water. C.f.u. were measured by pour plating and sensitivity was recorded as c.f.u./(c.f.u. at time zero). Horizontal dashed lines indicate the detection limits. Lines represent modelled inactivation curves with the program GInaFIT (Geeraerd et al., 2005). Empty diamonds $(\diamond)$ represent averaged controls. (a) Artificial UVA light was applied at the following intensities: $\times, 163 \mathrm{~W} \mathrm{~m}^{-2}$;, $332 \mathrm{~W} \mathrm{~m}^{-2} ; \bigcirc, 370 \mathrm{~W} \mathrm{~m}^{-2}$; $710 \mathrm{~W} \mathrm{~m}^{-2} ;+, 732 \mathrm{~W} \mathrm{~m}^{-2} ; \square, 786 \mathrm{~W} \mathrm{~m}^{-2} ;-, 802 \mathrm{~W} \mathrm{~m}^{-2} ; \boldsymbol{\Delta}$, $919 \mathrm{~W} \mathrm{~m}^{-2}$ and $\triangle, 1315 \mathrm{~W} \mathrm{~m}^{-2}$. (b) Sunlight irradiation on three different days in biologically independent triplicates: $\times, 0$ and $\bigcirc$ on 23 August 2006; $\mathbf{\square},+$ and $\square$ on 31 August 2006; -, $\boldsymbol{\Delta}$ and $\triangle$ on 25 July 2006 .

one day of solar irradiation $\left(8 \mathrm{~h} ; 2300\right.$ and $2500 \mathrm{~kJ} \mathrm{~m}^{-2}$, respectively). Efflux pump activity and ATP concentration had reached their lowest level by the end of the day (Figs $2 \mathrm{~b}, \mathrm{e}$ and $3 \mathrm{~b}, \mathrm{e})$. In contrast, inactivation of glucose uptake ability, loss of membrane potential and loss of membrane integrity were not observed with S. typhimurium and Sh. flexneri during one day of sunlight irradiation (Figs $2 \mathrm{f}, \mathrm{c}, \mathrm{d}$ and $3 \mathrm{f}, \mathrm{c}, \mathrm{d})$. Therefore, we decided to continue exposure on the next day.

Interestingly, S. typhimurium and Sh. flexneri lost cellular activity during dark storage at $37^{\circ} \mathrm{C}$ overnight. This is clearly shown for S. typhimurium, where an additional one$\log$ reduction in c.f.u. was observed after the night break (Fig. 2a). Accordingly, $60 \%$ of the cells lost their membrane potential during the night break and a slight reduction in membrane integrity was also observed (Fig. 2b). Furthermore, the percentage of cells able to take up glucose increased by $40 \%$ on the first day and was followed by a loss of $80 \%$ during the night break (Fig. 2f). ATP concentration and efflux pump activity reached their lowest level on the first day of irradiation (Fig. 2b, e). Interestingly, a more than twofold increase in ATP concentration was observed initially before it rapidly decreased at approximately $1000 \mathrm{~kJ} \mathrm{~m}^{-2}$. A similar increase in cellular activity with increasing exposure in the initial phase was observed also for the uptake of the fluorescent glucose analogue (see above).

For Sh. flexneri a similar general pattern was observed, but with some distinct differences in the magnitude of the effects. Culturability dropped over more than 3 additional log-units during the night break (Fig. 3a). After the night break, $80 \%$ of the cells had lost their membrane potential and $20 \%$ were even permeabilized (Fig. 3c, d). About $40 \%$ of the cells were unable to take up glucose (Fig. 3f). As in $S$. typhimurium, ATP concentration and efflux pump activity in Sh. flexneri had already reached final levels on the first day. Comparable to S. typhimurium, a slight increase in glucose uptake activity was observed during irradiation on the first day (Fig. 3d).

The overall fluence rate resulting in membrane permeabilization in $>90 \%$ of the cells ( 8000 vs $4500 \mathrm{~kJ} \mathrm{~m}^{-2}$ in $S$. typhimurium, and $6000 \mathrm{vs} 4500 \mathrm{~kJ} \mathrm{~m}^{-2}$ in Sh. flexneri) and loss of membrane potential in $>90 \%$ of the cells (6000 vs $2300 \mathrm{~kJ} \mathrm{~m}^{-2}$ in S. typhimurium, and 4500 vs $2500 \mathrm{~kJ} \mathrm{~m}^{-2}$ in Sh. flexneri) was clearly reduced with discontinuous irradiation (Table 1).

\section{Dark storage of S. typhimurium after irradiation}

For a better understanding of the overnight processes in the outdoor experiments, irradiation and subsequent storage in the dark of S. typhimurium was investigated in the laboratory (Fig. 4). This was done because of the higher resistance of $S$. typhimurium resulting in only 2-log reduction during one full day of exposure. Bacterial cell suspensions were irradiated with a dose of $1500 \mathrm{~kJ} \mathrm{~m}^{-2}$, corresponding to half a day of sunlight or one full day of exposure under overcast conditions. Culturability, efflux pump activity, membrane potential, membrane permeability and ATP content per cell were measured immediately after exposure and for a period of up to $48 \mathrm{~h}$ at eight subsequent time points during storage in the dark. This aspect was investigated in more detail because it is possible that a small part of the cells might survive the irradiation and that these survivors might start growing on either lysed cells or assimilable organic carbon in the water. For example, it has been shown that some pathogenic bacteria are able to grow on natural substrates in bulk water (Vital et al., 2007, 2008). To exclude this possibility and to make sure that only the cells originally exposed to light were analysed, we added nalidixic acid to inhibit cell division. The concentration of nalidixic acid required to keep $S$. typhimurium from dividing was determined in a minimal inhibitory concentration experiment.

After the bacteria had received a 'half-day' UVA dose, c.f.u. had decreased by approximately 1 log-unit (Fig. 4a). 

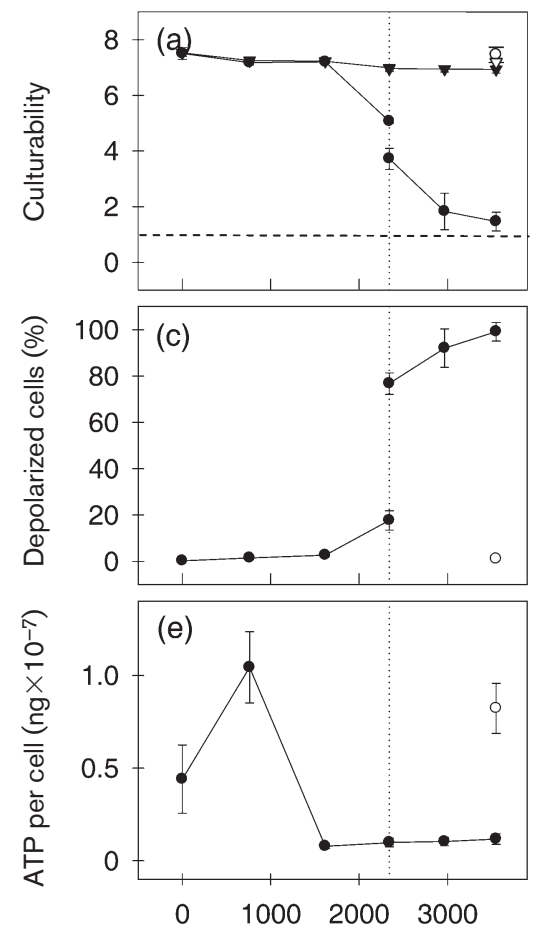

Fluence $\left(\mathrm{kJ} \mathrm{m}^{-2}\right)$
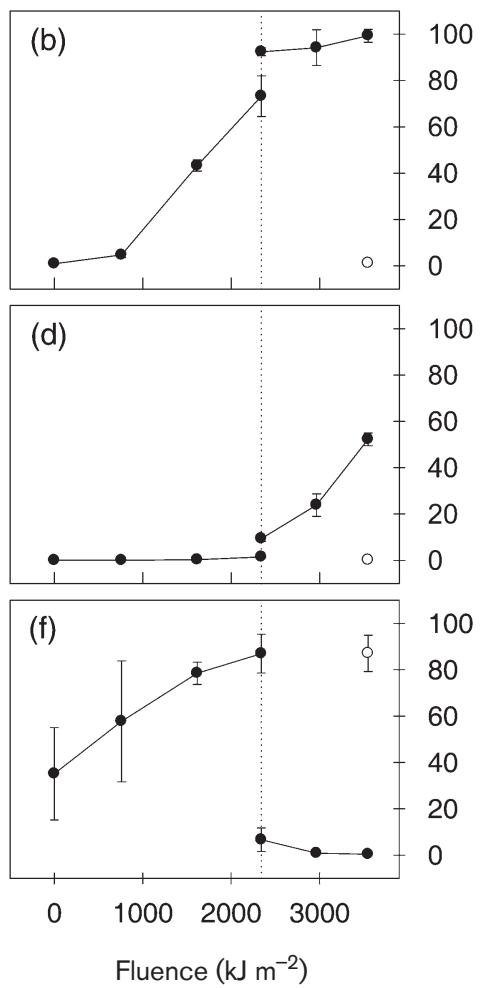

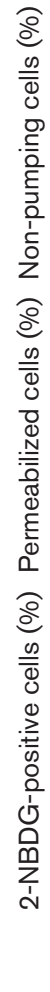

Fig. 2. Viability parameters of stationaryphase cells of $S$. typhimurium exposed to sunlight. (a) Culturability $\left[\log \left(\right.\right.$ c.f.u. $\left.\left.\mathrm{ml}^{-1}\right)\right](\bullet)$, with the dashed line indicating the detection limit, and log(total cell concentration $\left.\mathrm{ml}^{-1}\right)(\boldsymbol{\nabla})$. (b) EB-positive cells, (c) $\mathrm{DiBAC}_{4}$ (3)-positive cells, (d) PI-positive cells. Values were calculated as percentage of total cell concentration. (e) Average ATP concentration per cell. (f) 2NBDG-positive cells (able to take up glucose) calculated as percentage of total cell concentration. Light dose on day $1,2300 \mathrm{~kJ} \mathrm{~m}^{-2}$; day 2, $1200 \mathrm{~kJ} \mathrm{~m}^{-2}$ (overcast conditions). The night break is indicated by a dotted line in each graph. In all graphs, unirradiated control samples are displayed as empty symbols. Error bars represent standard deviations from three biologically independent experiments.
During subsequent dark storage, c.f.u. decreased by 5 logunits over $24 \mathrm{~h}$. Efflux pump activity was lost completely just after irradiation and was not regained (Fig. 4b). The unirradiated control cells were also hampered at the beginning of the experiment, when about $50 \%$ of the population showed no efflux pump activity, probably as an
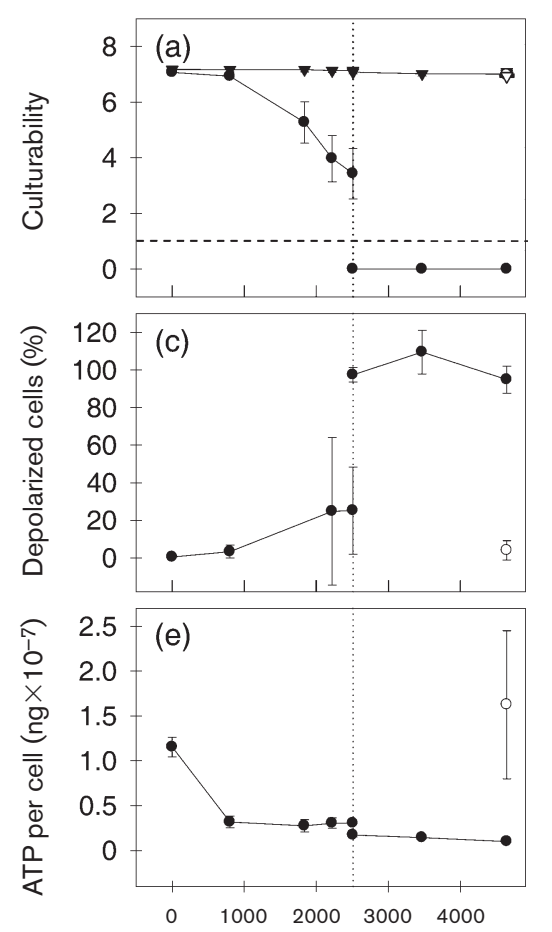

Fluence $\left(\mathrm{kJ} \mathrm{m}^{-2}\right)$
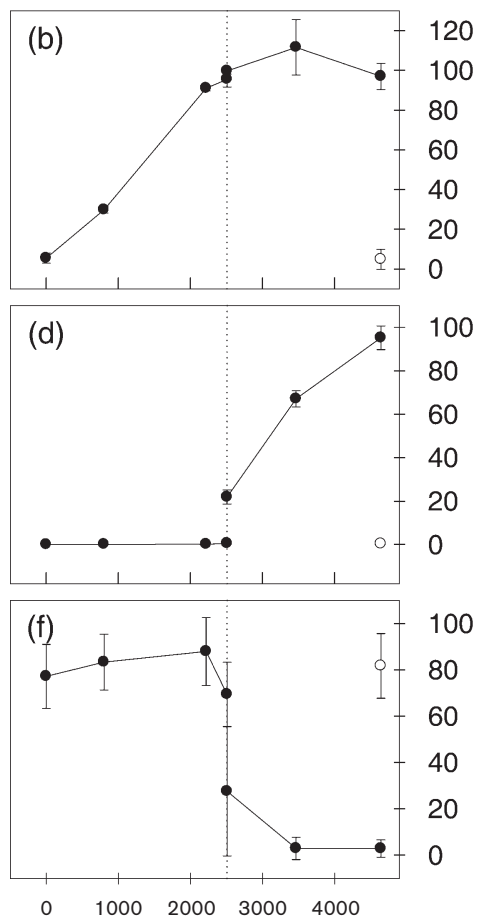

Fluence $\left(\mathrm{kJ} \mathrm{m}^{-2}\right)$

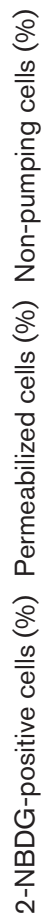

Fig. 3. Viability parameters of stationaryphase cells of Sh. flexneri exposed to sunlight. (a) Culturability $\left[\log \left(\right.\right.$ c.f.u. $\left.\left.\mathrm{ml}^{-1}\right)\right](\bullet)$, with the dashed line indicating the detection limit, and log(total cell concentration $\mathrm{ml}^{-1}$ ) ( $\left.\boldsymbol{\nabla}\right)$. (b) EBpositive cells, (c) $\mathrm{DiBAC}_{4}(3)$-positive cells, (d) $\mathrm{Pl}$-positive cells. Values were calculated as percentage of total cell concentration. (e) Average ATP concentration per cell. (f) 2NBDG-positive cells (able to take up glucose) calculated as percentage of total cell concentration. Light dose on day $1,2500 \mathrm{~kJ} \mathrm{~m}^{-2}$; day 2, $1300 \mathrm{~kJ} \mathrm{~m}^{-2}$ (overcast conditions). The night break is indicated by a dotted line in each graph. In all graphs, non-irradiated control samples are displayed as empty symbols. Error bars represent standard deviations from three biologically independent experiments. 

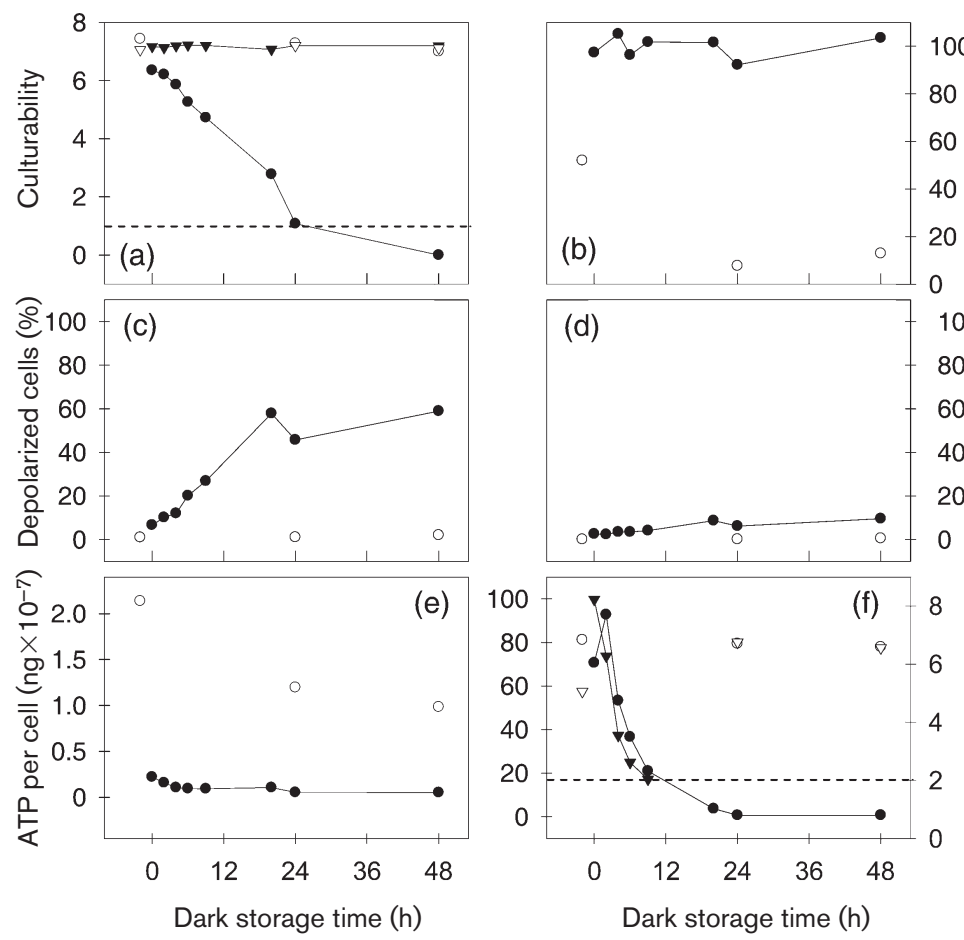

Fig. 4. Dark storage of $S$. typhimurium after exposure to a dose of $1500 \mathrm{~kJ} \mathrm{~m}^{-2}$ artificial UVA light, applied with an irradiation intensity of $205 \mathrm{~W} \mathrm{~m}^{-2}$ for $120 \mathrm{~min}$. To exclude the possibility of regrowth, nalidixic acid $(100 \mu \mathrm{g}$ $\mathrm{ml}^{-1}$ ) was included in all samples. (a) Culturability [log(c.f.u. $\left.\left.\mathrm{ml}^{-1}\right)\right](\bullet)$, with the dashed line indicating the detection limit, and log (total cell concentration $\mathrm{ml}^{-1}$ ) ( $\left.\mathbf{\nabla}\right)$. (b) EBpositive cells, (c) $\operatorname{DiBAC}_{4}$ (3)-positive cells, (d) $\mathrm{PI}$-positive cells. Values were calculated as percentage of total cell concentration. (e) Average ATP concentration per cell. (f) 2NBDG-positive cells (able to take up glucose), calculated as percentage of total cell concentration ( $\bullet$ numbers on left side of graph), and geometric mean of green fluorescence of the 2-NBDG-positive cell population ( $\boldsymbol{\nabla}$, numbers on right side of graph and dashed line for detection limit). In all graphs, non-irradiated control samples are displayed as empty symbols.

effect of nalidixic acid. Efflux pump activity was later regained in the control sample. Membrane potential was lost in only a very small part of the cell population during irradiation, but a relevant fraction of the cells (about $60 \%$ ) lost their membrane potential in the following $24 \mathrm{~h}$ of dark storage (Fig. 4c). Integrity of the cell membranes did not change significantly during dark storage: only a slight increase in the percentage of permeabilized cells was observed (Fig. 4d). ATP content of the cells was reduced to $10 \%$ compared to the control just after the treatment and levelled off to $<5 \%$ during the first $10 \mathrm{~h}$ after the treatment. Also the fraction of cells able to take up glucose decreased from about $90 \%$ just after the treatment to zero during the first $24 \mathrm{~h}$. The population that was still able to take up glucose during dark storage became increasingly less fluorescent, which indicates that the uptake rate of fluorescently labelled glucose decreased with time.

We never observed a regain of culturability in irradiated $S$. typhimurium or Sh. flexneri cells after $24 \mathrm{~h}$ or $48 \mathrm{~h}$ dark storage after irradiation with different light doses in laboratory or field experiments (data not shown).

\section{DISCUSSION}

\section{Susceptibility of S. typhimurium and Sh. flexneri to solar light}

For the first time, cellular functions in S. typhimurium and Sh. flexneri during solar and UVA exposure were followed not only by plating but also with viability staining and ATP measurements. The pattern of sequential loss of cellular functions during continuous artificial UVA exposure was similar in both tested organisms and corroborates our results for E. coli (Berney et al., 2006a). The similarity in inactivation pattern suggests that the molecular mechanisms involved in the inactivation and killing of bacterial pathogens due to solar irradiation are similar or even identical in the three enteric bacteria. Therefore, E. coli can be considered a good model organism for such investigations. However, as suggested in an earlier study (Berney et al., 2006b), both Sh. flexneri and S. typhimurium were found to be more resistant than E. coli.

\section{Light dose reciprocity in SODIS}

In experiments with Sh. flexneri and S. typhimurium, we observed two modes of exposure that caused deviation from the reciprocity law: firstly, exposure to either very high or very low irradiation intensity, and secondly, split exposure by a pause in irradiation of up to $14 \mathrm{~h}$. Interestingly, light dose reciprocity was valid for $E$. coli (Berney et al., 2006b) and S. typhimurium (this study) within a much broader intensity range $\left(50-700 \mathrm{~W} \mathrm{~m}^{-2}\right.$ ) than for Sh. flexneri, which already showed distinct deviation when light intensities were two- to threefold higher than those occurring under natural conditions.

\section{High irradiation intensity reduces the light dose required for inactivation}

Light dose reciprocity has been observed in a majority of biological and medical applications, while so called 'reciprocity law failures' have been mostly observed in 
experiments conducted at either very low or very high radiant fluxes (Martin et al., 2003). In the case of Sh. flexneri irradiated with UVA light we observed that the shoulder of the inactivation curve became less pronounced or was even eliminated with high irradiation intensities. The existence of a shoulder was interpreted earlier by either the presence of repair mechanisms that are able to slow down the light effect and/or damage to more than one target within the cell (Harm, 1980; Sommer et al., 2001). If a shoulder is eliminated, as seen in our experiments for high-intensity irradiation of Sh. flexneri and also $S$. typhimurium, repair mechanisms might be too slow or damaged themselves. Elimination of the shoulder results in a reduction of the light dose required for inactivation.

\section{Split exposure reduces the light dose required for inactivation}

We found that S. typhimurium and Sh. flexneri are more susceptible to the same light dose when exposed to sunlight over two days (with a break overnight) than with continuous artificial UVA light. This finding was reproduced in the laboratory with discontinuous irradiation on two consecutive days (data not shown). This is most likely because the bacterial cells are irreversibly damaged and consequently they continue to lose viability even when irradiation is stopped.

This is in line with the observation that exposure of cells from a human carcinoma cell line to short intervals of UVA light was more cytotoxic than continuous UVA irradiation (Merwald et al., 2005). However, if the time between exposures exceeded $2 \mathrm{~h}$, the cells were able to recover and, therefore, were less susceptible than with one single dose of UVA. Similar results were reported for Saccharomyces cervisiae and E. coli irradiated with UVC light (Dzidic et al., 1986; Harm, 1968; Salaj-Smic et al., 1985; Sommer et al., 1996) and human dermal fibroblasts irradiated with UVA light (tanning bed radiation) (Hoerter et al., 2008). Therefore, our data suggest either that the repair mechanisms of S. typhimurium and Sh. flexneri were already inactivated after $8 \mathrm{~h}$ of continuous irradiation, or that the lack of nutrients in the suspension did not allow the induction of an appropriate repair response. It remains to be determined whether or not the cells are able to recover when cell damage is less severe (shorter irradiation period) or when an appropriate amount of nutrients is available in the water.

Discontinuous UVC exposure of E. coli was shown to induce the SOS response, which increases DNA repair activity (Dzidic et al., 1986; Salaj-Smic et al., 1985). However, UVA probably causes more complex damage to the cells (several targets may be affected by UVA light, as compared to UVC, where predominantly DNA damage is observed) (Jagger, 1981). Hence, this is likely to require a more complex repair machinery. In an earlier microarray study we showed that in E. coli both DNA-repair genes and genes involved in oxidative stress response are induced upon irradiation with sublethal UVA light intensities (Berney et al., 2006c).

\section{Inactivation mechanism of SODIS}

The data presented in this study strongly suggest that SODIS inactivates S. typhimurium and Sh. flexneri by inhibiting the respiratory chain. The ATP content per cell decreased rapidly in E. coli (Berney et al., 2006a) and Sh. flexneri (this study) upon irradiation with sunlight, while in S. typhimurium an initial increase was observed before a sharp sustained decline. We propose that after an initial activation of energy metabolism, which is reflected in increased glucose uptake and ATP level, respiration stops and the remaining ATP is either consumed by various recovery processes (Kobayashi et al., 2005), or, more likely, through the maintenance of the membrane potential via the $\mathrm{F}_{1} \mathrm{~F}_{0}$-ATPase. Consistent with this proposal is the observed increase in glucose uptake activity, which provides ATP via substrate-level phosphorylation to fuel the proton-pumping ATPase to maintain the membrane potential at a critical level even in the absence of a functioning electron-transport chain. Since the medium used in this study (bottled mineral water) contains only low levels of assimilable organic carbon, the cells will eventually die from ATP exhaustion and loss of the membrane potential. In fact, it has been proposed earlier that components of the respiratory chain like menaquinones and dehydrogenases could be inactivated by UVA light (Jagger, 1981).

\section{Repair and regrowth}

In our experiments, injured bacterial cells irradiated with sunlight or UVA light were never observed to be able to regrow. This corroborates the work of other authors (Joyce et al., 1996; Oates et al., 2003; Reed, 1997; Wegelin et al., 1994).

The lack of regrowth in cells irradiated with polychromatic UV light in water disinfection processes seems to be the main advantage compared to monochromatic UVC light and therefore is of great interest to the water disinfection community (Kalisvaart, 2001, 2004; Oguma et al., 2002; Zimmer-Thomas et al., 2007).

It has been shown that non-cultivable cells of $S$. typhimurium produced by UVA irradiation do not retain infectivity for mice (Smith et al., 2000). Our study now indicates that this is most likely due to irreversible damage occurring during exposure to sunlight. Bacterial cells that are impaired in glucose uptake and oxidative phosphorylation may not be able to regrow, because uptake of nutrients and the maintenance of a membrane potential are regarded as prerequisites for survival and replication.

\section{Conclusion and implications for practice}

SODIS and artificial UVA light kill enteric bacteria most likely by inactivation of the respiratory chain and subsequent exhaustion of ATP. Our results show that even the resistant strain of S. typhimurium, which appeared to suffer only minor damage after half a day of sunlight, was 
actually damaged to an extent such that regain of viability was not detected. In fact, our results suggest that it is even favourable to store the treated water overnight before consumption, because injured cells will die from ATP exhaustion.

\section{ACKNOWLEDGEMENTS}

This project was financially supported by the Velux Foundation (project number 346). We thank Margarete Bucheli, Martin Wegelin, Regula Meierhofer, Silvio Canonica and Gregory M. Cook for valuable discussions.

\section{REFERENCES}

Acra, A., Karahagopian, Y., Raffoul, Z. \& Dajani, R. (1980), Disinfection of oral rehydration solutions by sunlight. Lancet 316, 1257-1258.

Berney, M., Weilenmann, H.-U. \& Egli, T. (2006a). Flow-cytometric study of vital cellular functions in Escherichia coli during solar disinfection (SODIS). Microbiology 152, 1719-1729.

Berney, M., Weilenmann, H.-U., Ihssen, J., Bassin, C. \& Egli, T. (2006b). Specific growth rate determines the sensitivity of Escherichia coli to thermal, UVA and solar disinfection. Appl Environ Microbiol 72, 2586-2593.

Berney, M., Weilenmann, H. U. \& Egli, T. (2006c). Gene expression of Escherichia coli in continuous culture during adaptation to artificial sunlight. Environ Microbiol 8, 1635-1647.

Berney, M., Hammes, F., Bosshard, F., Weilenmann, H. U. \& Egli, T. (2007). Assessment and interpretation of bacterial viability by using the LIVE/DEAD BacLight Kit in combination with flow cytometry. Appl Environ Microbiol 73, 3283-3290.

Berney, M., Vital, M., Hülshoff, I., Weilenmann, H.-U., Egli, T. \& Hammes, F. (2008). Rapid, cultivation-independent assessment of microbial viability in drinking water. Water Res 42, 4010-4018.

Dzidic, S., Salaj-Smic, E. \& Trgovcevic, Z. (1986). The relationship between survival and mutagenesis in Escherichia coli after fractionated ultraviolet irradiation. Mutat Res 173, 89-91.

Geeraerd, A. H., Valdramidis, V. P. \& Van Impe, J. F. (2005). GInaFiT, a freeware tool to assess non-log-linear microbial survivor curves. Int J Food Microbiol 102, 95-105.

Harm, W. (1968). Effects of dose fractionation on ultraviolet survival of Escherichia coli. Photochem Photobiol 7, 73-86.

Harm, W. (1980). Biological Effects of Ultraviolet Radiation. Cambridge: Cambridge University Press.

Hoerter, J. D., Ward, C. S., Bale, K. D., Gizachew, A. N., Graham, R., Reynolds, J., Ward, M. E., Choi, C., Kagabo, J. L. \& other authors (2008). Effect of UVA fluence rate on indicators of oxidative stress in human dermal fibroblasts. Int J Biol Sci 4, 63-70.

Jagger, J. (1981). Near-UV radiation effects on microorganisms. Photochem Photobiol 34, 761-768.

Joyce, T. M., McGuigan, K. G., Elmore-Meegan, M. \& Conroy, R. M. (1996). Inactivation of fecal bacteria in drinking water by solar heating. Appl Environ Microbiol 62, 399-402.

Kalisvaart, B. F. (2001). Photobiological effects of polychromatic medium pressure UV lamps. Water Sci Technol 43, 191-197.

Kalisvaart, B. F. (2004). Re-use of wastewater: preventing the recovery of pathogens by using medium-pressure UV lamp technology. Water Sci Technol 50, 337-344.
Kobayashi, H., Miyamoto, T., Hashimoto, Y., Kiriki, M., Motomatsu, A., Honjoh, K. \& lio, M. (2005). Identification of factors involved in recovery of heat-injured Salmonella Enteritidis. J Food Prot 68, 932-941.

Martin, J. W., Chin, J. W. \& Nguyen, T. (2003). Reciprocity law experiments in polymeric photodegradation: a critical review. Prog Org Coat 47, 292-311.

McGuigan, K. G., Joyce, T. M., Conroy, R. M., Gillespie, J. B. \& Elmore-Meegan, M. (1998). Solar disinfection of drinking water contained in transparent plastic bottles: characterizing the bacterial inactivation process. J Appl Microbiol 84, 1138-1148.

Merwald, H., Klosner, G., Kokesch, C., Der-Petrossian, M., Honigsmann, H. \& Trautinger, F. (2005). UVA-induced oxidative damage and cytotoxicity depend on the mode of exposure. $J$ Photochem Photobiol B 79, 197-207.

Natarajan, A. \& Srienc, F. (2000). Glucose uptake rates of single E. coli cells grown in glucose-limited chemostat cultures. J Microbiol Methods 42, 87-96.

Oates, P. M., Shanahan, P. \& Polz, M. F. (2003). Solar disinfection (SODIS): simulation of solar radiation for global assessment and application for point-of-use water treatment in Haiti. Water Res 37, $47-54$.

Oguma, K., Katayama, H. \& Ohgaki, S. (2002). Photoreactivation of Escherichia coli after low- or medium-pressure UV disinfection determined by an endonuclease sensitive site assay. Appl Environ Microbiol 68, 6029-6035.

Reed, R. H. (1997). Solar inactivation of faecal bacteria in water: the critical role of oxygen. Lett Appl Microbiol 24, 276-280.

Rose, A., Roy, S., Abraham, V., Holmgren, G., George, K., Balraj, V., Abraham, S., Muliyil, J., Joseph, A. \& Kang, G. (2006). Solar disinfection of water for diarrhoeal prevention in southern India. Arch Dis Child 91, 139-141.

Salaj-Smic, E., Dzidic, S. \& Trgovcevic, Z. (1985). The effect of a split UV dose on survival, division delay and mutagenesis in Escherichia coli. Mutat Res 144, 127-130.

Smith, R. J., Kehoe, S. C., McGuigan, K. G. \& Barer, M. R. (2000). Effects of simulated solar disinfection of water on infectivity of Salmonella typhimurium. Lett Appl Microbiol 31, 284-288.

Sommer, R., Haider, T., Cabaj, A., Heidenreich, E. \& Kundi, M. (1996). Increased inactivation of Saccharomyces cerevisiae by protraction of UV irradiation. Appl Environ Microbiol 62, 1977-1983.

Sommer, R., Pribil, W., Appelt, S., Gehringer, P., Eschweiler, H., Leth, H., Cabaj, A. \& Haider, T. (2001). Inactivation of bacteriophages in water by means of non-ionizing (UV-253.7 nm) and ionizing (gamma) radiation: a comparative approach. Water Res 35, 31093116.

Vital, M., Fuchslin, H. P., Hammes, F. \& Egli, T. (2007). Growth of Vibrio cholerae O1 Ogawa Eltor in freshwater. Microbiology 153, 19932001.

Vital, M., Hammes, F. \& Egli, T. (2008). Escherichia coli O157 can grow in natural freshwater at low carbon concentrations. Environ Microbiol 10, 2387-2396.

Wegelin, M., Canonica, S., Mechsner, K., Fleischmann, T., Pesaro, F. \& Metzler, A. (1994). Solar water disinfection: scope of the process and analysis of radiation experiments Aqua 43, 154-169.

Zimmer-Thomas, J. L., Slawson, R. M. \& Huck, P. M. (2007). A comparison of DNA repair and survival of Escherichia coli O157:H7 following exposure to both low- and medium-pressure UV irradiation. J Water Health 5, 407-415.

Edited by: D. M. Gordon 